\title{
An Integrated Structural Equation Modeling and Analytic Hierarchy Process Approach to Prioritize Investment in the Construction Industry to Achieve Sustainable Development in Saudi Arabia
}

\author{
Mohamed Mansour ${ }^{1,2 *}$, Shaik Dawood ${ }^{2}$, Ibrahim Falqi ${ }^{3}$ \\ ${ }^{1}$ Industrial Engineering Department, College of Engineering, Zagazig University, Zagazig, Egypt \\ ${ }^{2}$ Industrial Engineering Department, College of Engineering, King Khalid University, Abha, Saudi Arabia \\ ${ }^{3}$ Civil Engineering Department, College of Engineering, King Khalid University, Abha, Saudi Arabia
}

Received: 9 February 2019

Accepted: 7 July 2019

\begin{abstract}
The construction industry is a major contributor to socio economic development and an extensive user of energy and natural resources; therefore, its engagement is fundamental to sustainability. This research prioritizes investment spending in the construction sector in Saudi Arabia to meet sustainable development. This research uses integrated structure equation modeling (SEM) and analytical hierarchy process (AHP) as a solution approach for prioritizing the alternatives for the decision maker. Experts and decision makers have been interviewed to define the main and subcriteria and the corresponding pairwise comparison matrix. Economic, environmental, and social (EES) criteria were considered, including 8, 8, and 5 subcriteria, respectively. SmartPLS applying the partial least squares structural equation modeling (PLS-SEM) method and expert choice for AHP were used to rank investment in the construction sector in Saudi Arabia in order to attain sustainable development. The SEM results revealed that the influencing factors are 5 economic, 5 environmental, and 3 social subcriteria in sustainable development. The results indicated that building projects ranked first at $13.9 \%$, followed by water and sanitation activities at $11.2 \%$, and by electrical works business at $10.8 \%$. Road work ranked fourth at $8.6 \%$, accompanied by mechanical activities at $6.4 \%$. The electronic works category ranked sixth at $6.2 \%$, and then landscaping works at $4.8 \%$. The dams category ranked eighth at $3.3 \%$; city cleaning and waste disposal achieved a percentage of $3.1 \%$, and the remaining categories achieved percentages of between $0.07 \%$ and $1.9 \%$. The recommendations were that the Saudi government
\end{abstract}

*e-mail: momansor@kku.edu.sa 
should provide an investment preference in any future development plan for activities that received the highest priority in the AHP model.

Keywords: multicriteria decision making, environmental sustainability, construction industry, statistical analysis

\section{Introduction}

Sustainable development (SD) requires considering economic, environmental, and social (EES) aspects of industrial activities as key factors for development [1,2]. Industrial investment, especially investment spending on the construction sector, is one of the main pillars of economic development. Any industrial activity is accompanied by air emissions, which are suspended particles or hazardous/normal wastes that affect the internal working and external environment. Investment in industrial activities must be ensured for sustainability to ensure profitable and safe industrial development. The fundamental problem is the lack of an estimate of basic SD dimension weights for EES criteria to assess the importance of industrial activities [3-6].

The construction sector is one of the most influential sectors in the economy for the rest of the world [7]. This sector is a vital pillar upon which many economic activities rest, and an important one to contribute to developing income levels, increasing the growth rate and diversifying the economic base. The sector plays a key role in generating jobs and addressing social and environmental issues resulting from rapid population growth and increasing urbanization, reflecting its significant impact on SD. The importance of the construction sector in the Kingdom of Saudi Arabia (KSA) is reflected in its position in the national economy. In 2012, the sector's contribution to gross domestic product (GDP) at constant prices was $7.15 \%$, and its total number of employment was $18.8 \%$ [8]. The sector has a great deal of interest from the state represented by the volume of its spending on infrastructure projects in order to maintain pace with societal and economic development. In financial year 2017/2018, the general budget expenditure was estimated at 820 billion Saudi riyals (SRs) and revenue of SR 285 billion, representing more than $38 \%$ of the total estimated budget expenditure [9].

The KSA has experienced an unprecedented rise in construction projects during the last 20 years [10]. A massive amount of waste (municipal/industrial/ communal) is generated by the construction industry, and the KSA government issued a decree that requires construction firms to meet new consumption standards in order to decrease the impact of waste in their construction activity [11]. The growing demographics of KSA urges strong and sustainable demand, and with 66 percent of the population under the age of 25 , the demand for social and economic sustainability will continue. In this research work, 29 construction sectors were chosen: buildings, electrical works, water and sanitation works, roads, mechanical works, electronic works, landscaping, city cleaning and communal waste disposal, dams, maintenance and operation of industrial works, communication technology, maintenance of buildings, catering for medical centers, maintenance of roads, maintenance of landscaping, maintenance and operation of electrical works, maintenance and operation of water and sanitation works, maintenance and operation of mechanical works, industrial works, maintenance and operation of marine works, catering for individuals, maintenance and operation of electronic works, marine works, maintenance of health centers, maintenance and operation of slaughterhouses, slaughterhouses, well drilling, maintenance and operation of communication technology, and maintenance and operation of dams (for a total of 18,573 companies) [12]. Economic growth, social equity, and ecological awareness can be achieved through public participation toward sustainability [13]. Government involvement and support are further considered important for enforcing the adoption of sustainable improvement.

In this research work, the EES sustainable factor weights are calculated in addition to their subfactor weights. The research data are reinforced with information distilled from interviews conducted with managers and experts working in construction companies. The ranking is based on the multicriteria decision-making approach; hence, it highlights a clear view on the most effective priority factors. The SEM approach is used to define the effective factors in an SD evaluation. In the literature, the majority of the work done concentrates on using a multicriteria decisionmaking (MCDM) technique to prioritize the most effective factors in an SD evaluation without considering the effectiveness of these factors in SD. SmartPLS [14] and Expert Choice [15] software were used in this research to evaluate the correlation between the main factors and subfactors to determine the importance of construction industry sector categories.

Based on the reported research, we noticed that no research existed to determine the weights of the main and subcriteria for SD, which determines the investment spent in the construction industry sector. Most of the work done used the AHP method of the MCDM approach to address sustainability research. The objective of this research is to define a priority weight for each main criterion and the subcriteria SD dimension in KSA to guide the decision maker to divide investment spending on each construction industry category. To achieve this objective, an SEM concept was applied to determine the affecting factors that contribute to a sensible change in SD in addition to an AHP model 
for prioritizing the investment spending proportion for each construction category.

The main question that arose in the minds of researchers is which construction sector industry is the most suitable choice to obtain SD for investing in the construction sector and what are the main and subcategories that affect the selection process and their weights? By assuming that a relationship between the major criteria does not exist, we tested whether the hypothesis of the EES criteria will influence SD for the construction industry sector. Currently, the construction industry is one of the main tools for allocating capital to productive activities. The importance of the construction industry is very high, such that this activity is one of the most important indices of economic growth. This research is highlighted to determine the value of allocating the general budget of KSA according to the weights of the major and subcriteria for SD and using it to determine priorities of investment spending on the construction industry in Saudi Arabia. The objective is to ensure that governmental and private sectors work in an SD environment.

Data required to define the SEM and AHP models were gathered from governmental and private companies functioning in 29 construction sector categories in KSA. The following methods were used to collect information: "face-to-face interviewing", "postal surveys", "telephone surveys", "direct observation", and the "internet" via questionnaires and conducted with managers and experts working in medium and large firms in 13 regions of the KSA. The data were collected during summer 2018 by 50 students in the Industrial Engineering Department, College of Engineering, King Khalid University. The sample was composed of 210 males only due to the social nature of the Saudi working environment. The next sections of the article review the literature, describe the solution method, summarize the results, and provide a conclusion and recommendations for future work.

Recently, SD has become an important issue in KSA, especially after adopting the Vision 2030 plan. KSA has set great ambitions for achieving SD to develop the capabilities of citizens, achieve their aspirations, meet their needs, and improve the standard of living as the highest goals of SD in the Kingdom, as well as to expand the scope of development to include all EES sectors in all regions. Construction activities are increasing in the current decade; therefore, it is an effective sustainability development topic. This study is focused on this matter because of the importance of SD on this issue.

This research is conducted in five important sections. In section 2, the literature is reviewed. The methodologies of the PLS-SEM and AHP models are illustrated in the third section. The fourth section applies the solution methodology to prioritize investment in the construction sector in Saudi Arabia based on the opinion and judgement of local experts. Finally, section 5 provides the conclusion and future work.

\section{Literature Review}

Multicriteria assessment is a tool for sustainability development decision making encompassing a wide choice of decision criteria [17] and risk assessment [18], and life cycle assessments [19] - which are essential tools for assessing alternatives. The sustainability research work is done in the fields of engineering [20], environmental science and ecology [21], health technology [22], construction building technology [23], material selection [24], business economics [25], and mathematics [26]. A hybrid MCDM based on step-wise weight assessment ratio analysis and complex proportional assessment compose a unified framework regarding environmental sustainability for establishing a five-star hotel in Tehran, Iran [27]. In this research, the stepwise weight assessment ratio analysis produces criteria values, and complex proportional assessments are used to rank decision alternatives. An AHPbased sustainability evaluation framework for midrise residential buildings based on a broad range of environmental and socioeconomic criteria is discussed in [28]. The researchers studied a cradle-to-grave life cycle assessment technique to find, classify, and assess triple bottom line sustainability performance indicators of buildings. Then, the AHP was applied to aggregate the impacts into a unified sustainability index. The researchers show the framework through a case study to investigate two six-story structural systems in Vancouver, Canada. The results indicate that the environmental performance of a building in Canada depends on service life energy more than structural materials. Also, an AHP sustainability assessment method that includes the main sustainability factors for consideration in industrial building construction, as well as other factors that greatly influence the conceptual design of the building, was provided as a tool for sustainability improvement in the construction industry.

The social sustainability of infrastructure was addressed by [29]. The authors reviewed the state of multicriteria infrastructure assessment studies that include social aspects. The review includes an analysis of the social criteria, participation and assessment methods. The results identify mobility and access, safety and local development among the most frequent criteria. The AHP and simple additive weighting methods are the most frequently used. However, treatments of equity, uncertainty, learning and consideration of the context are not properly analyzed yet. A weighting system for a refurbishment building assessment scheme in Malaysia was developed through the AHP approach to rank assessment themes and identify the priorities of the study's participating stakeholders [30]. The outcome is the Malaysian refurbishment assessment scheme, which includes a set of weightings and a classification system for the selected assessment themes and subthemes. The methods and findings can be adapted for use by other practitioners to develop building assessment schemes to pursue the goals of SD through refurbishment. 
An indicator-based approach is used to evaluate sustainability along different stages of petroleum refinery industry projects [31]. In addition, a multilevel hierarchy of criteria decision making was defined by using AHP, combined with fuzzy set theory to enhance the reliability of the results.

A hybrid MCDM model was proposed to evaluate the construction projects of hotels regarding environmental sustainability [32]. Stepwise weight assessment ratio analysis and complex proportional assessment compose a unified framework. A private construction project is supposed as a case study. The project is based on establishing a five-star hotel in Tehran, Iran. In this research, a stepwise weight assessment ratio analysis produces criteria weights and complex proportional assessment that will rank decision alternatives. A sustainability index was proposed that provides companies with information regarding their level of EES sustainability, showing their performance at both the individual and supply chain levels using AHP methodology [33]. The authors concluded that there is a low level of sustainability and more focus needs to be given to the social and environmental dimensions to affect future changes in behavior.

An AHP-fuzzy inference system model was presented to aid decision-makers in the risk assessment and mitigation of overseas steel-plant projects [34]. Through a thorough literature review, the authors identified 57 risks associated with international steel construction, operation, and transference of new technologies. Pairwise comparisons of all 57 risks by 14 subject-matter experts resulted in a relative weighting. Furthermore, to mitigate human subjectivity, vagueness, and uncertainty, a fuzzy analysis based on the findings of two case studies was performed. From these combined analyses, weighted individual risk scoring resulted in the following top five most impactful international steel project risks: procurement of raw materials, design errors and omissions, conditions of raw materials, technology spill prevention plan, investment cost, and poor plant availability and performance. Risk mitigation measures are also presented, and risk scores are re-assessed through the AHP-fuzzy inference system analysis model depicting an overall project risk score reduction.

An AHP methodology was proposed to customize an adapted weighting system that prioritizes the Saudi environmental assessment method categories [35]. Expert choice software was the main tool to analyze the input data. This research instrument involves the participation of a number of leading global experts in the field of environmental and SD, as well as professionals and highly informed local experts from government, academia, and industry. The results reveal that wellknown environmental assessment methods are not fully applicable to the Saudi built environment, as reflected in the resulting categories, criteria and weighting system of Saudi environmental assessment method. The application of 22 different MCDM methods belonging to this discipline in various areas of the construction industry was reviewed and clustered in 11 categories [36]. The most significant methods are briefly discussed, noting their principal strengths and limitations. Furthermore, the data gathered while writing this paper are statistically analyzed to identify different trends concerning the use of these techniques. The review shows the method's usefulness in characterizing very different decision-making environments, highlighting the reliability acquired by the most pragmatic and widespread methods and the emergent tendency to use some of them in combination. The sustainability assessment methodology was tested using the integrated value model for sustainable assessment, applied to industrial buildings [37]. In addition to traditional requirements, this noncommercial methodology involves other aspects of sustainability that are also important for establishing a means of evaluation. The methodology reliability is tested here through its application to three case studies. The integrated value model for a sustainable evaluation is an AHP-based MCDM methodology that can be applied in any field. In this study, the methodology's specific focus is on improvements to sustainability in construction.

System dynamics, AHP, utility theory, and fuzzy logic methodologies were combined to develop an assessment model for the green innovation of contractors [38]. System dynamics can be used to estimate the future trends for the overall industrial structure and is useful for predicting competitive advantage in industry. The AHP and utility theory focus on the customer's attitude toward risk and are useful for comprehending changes in objective requirements in the environment. Fuzzy logic can simplify complicated intrinsic and extrinsic factors and express them with a number or ratio that is easy to understand. The proposed assessment model can be used as a reference to guide the government in examining the public construction that qualified green contractors participate in.

Most of the work done addressing sustainabilityrelated judgment focuses on solving the problem with multicriteria decision-making using AHP or Fuzzy AHP. This research applies an integrated approach combining SEM and AHP. SEM defines the affecting factors in the decision-making process, and AHP defines the alternative weights. This investigation uses SmartPLS and Expert Choice software to design and analyze the collected data from Saudi experts working in construction industry categories. The results of the SEM analysis are applied in the AHP model. Expert Choice designed the AHP model that calculates the consistency ratio for judgments and values of the criteria and subcriteria of the total weights of alternatives.

\section{Materials and Methods}

This methodology supports the main idea of this study about prioritizing investment spending in the 


\begin{tabular}{|c|c|c|c|c|c|c|c|c|c|}
\hline 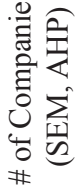 & $\begin{array}{l}\underset{f}{f} \\
\underset{\mathbb{J}}{\mathrm{N}} \\
\underline{\Omega}\end{array}$ & 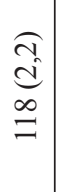 & $\begin{array}{l}\hat{\tilde{d}} \\
\tilde{d} \\
\tilde{d} \\
0\end{array}$ & $\begin{array}{l}\underset{\mathfrak{d}}{d} \\
\stackrel{d}{\infty}\end{array}$ & $\begin{array}{l}\widehat{\widehat{T}} \\
\mathfrak{d} \\
\infty \\
0\end{array}$ & $\begin{array}{l}\tilde{d} \\
\tilde{d} \\
\mathbb{8}\end{array}$ & $\begin{array}{l}\text { d } \\
\mathfrak{d} \\
g \\
g\end{array}$ & $\begin{array}{l}\underset{d}{d} \\
\underset{m}{n}\end{array}$ & 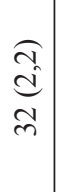 \\
\hline 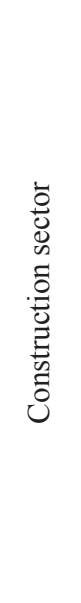 & 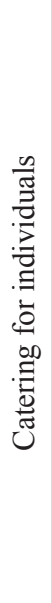 & 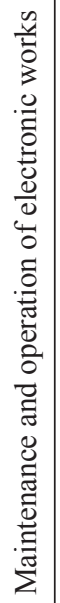 & 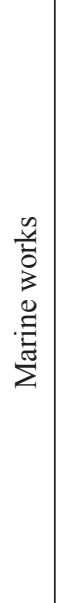 & 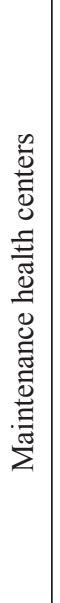 & 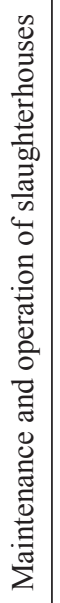 & 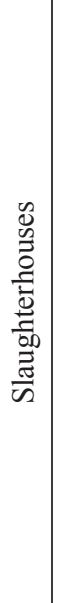 & 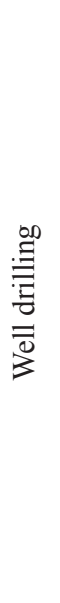 & 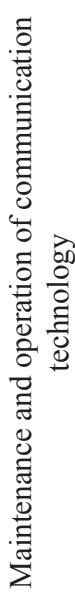 & 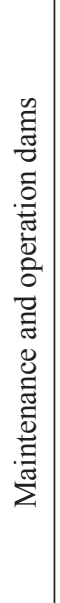 \\
\hline 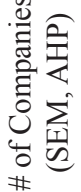 & 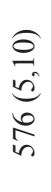 & $\begin{array}{l}\infty \\
\infty \\
m \\
m \\
i n\end{array}$ & 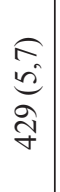 & $\begin{array}{l}\hat{\sigma} \\
\tilde{c} \\
0 \\
m \\
\text { nd }\end{array}$ & $\begin{array}{l}\underset{f}{n} \\
\tilde{n} \\
\tilde{n}\end{array}$ & 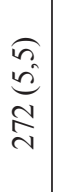 & $\begin{array}{l}n \\
n \\
n \\
\Omega \\
\Omega\end{array}$ & $\begin{array}{l}\widehat{\widetilde{d}} \\
\stackrel{d}{\infty} \\
\stackrel{0}{=}\end{array}$ & $\begin{array}{l}\underset{\mathfrak{d}}{d} \\
\stackrel{d}{\Xi} \\
=\end{array}$ \\
\hline
\end{tabular}

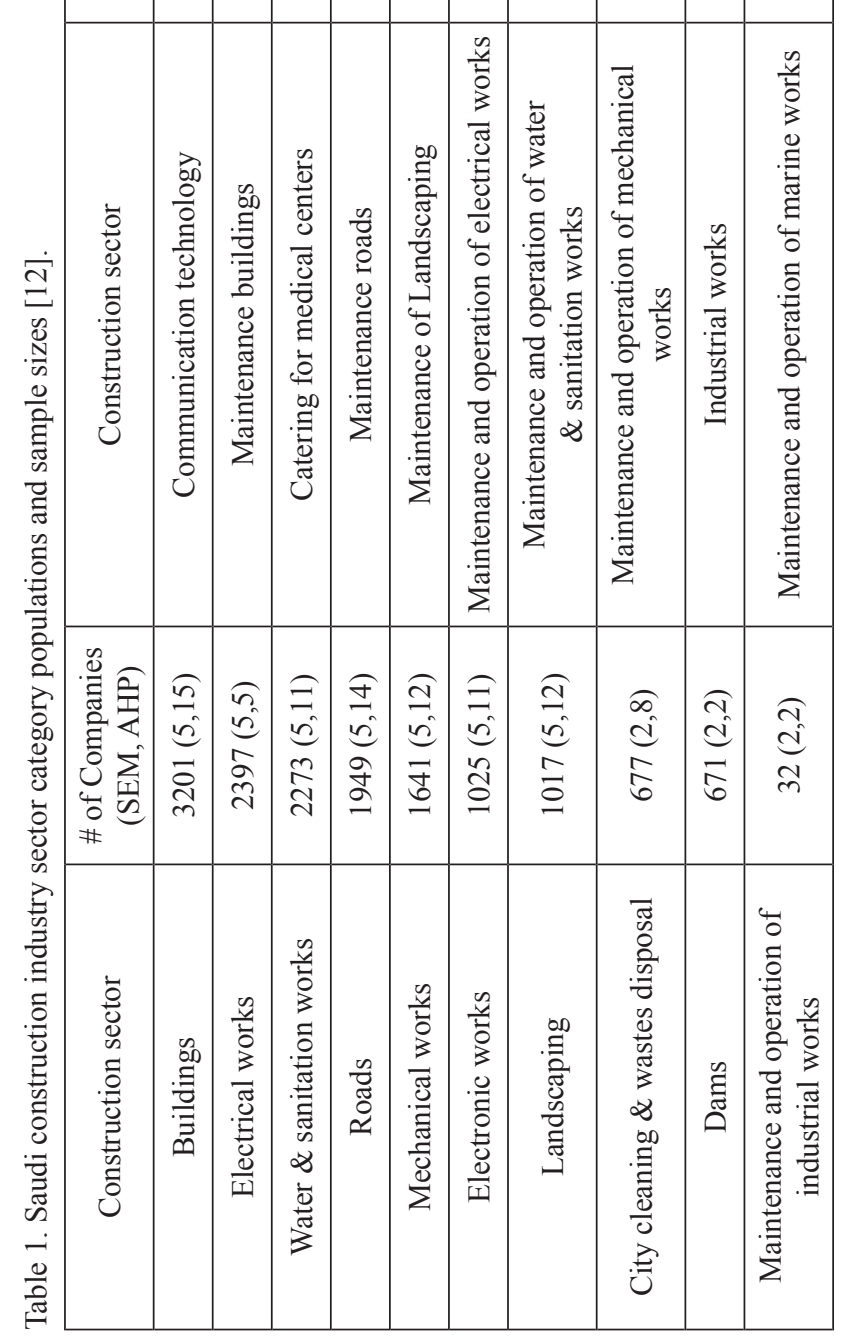

\begin{tabular}{|c|c|c|c|c|c|c|c|}
\hline$\frac{8}{8}$ & 䓛 & $\sum_{I I}^{N}$ & $\sum_{I}^{m}$ & $\sum_{I}^{+}$ & & $\sum_{-1}^{0}$ & 空 \\
\hline
\end{tabular}

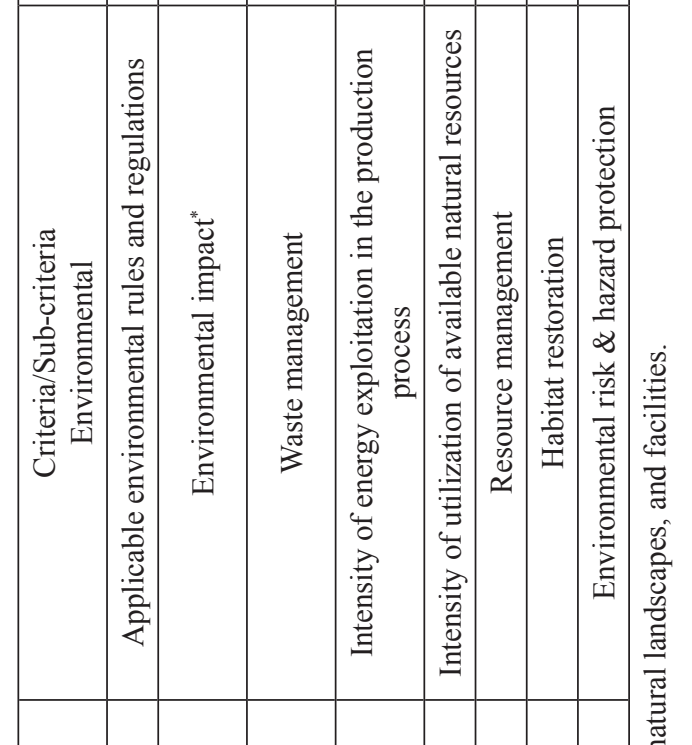

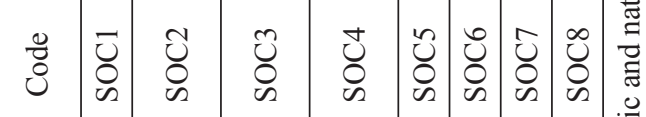

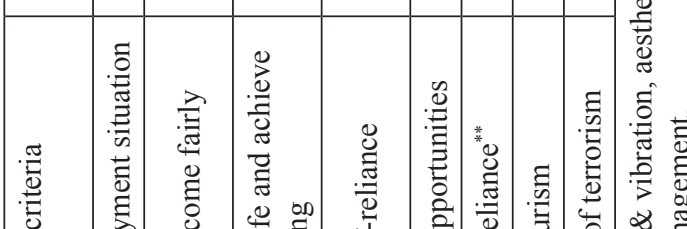

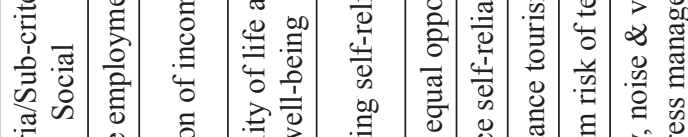

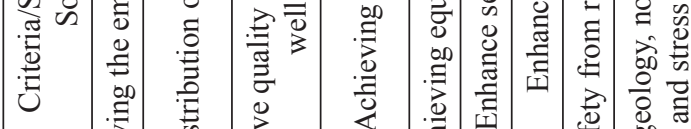

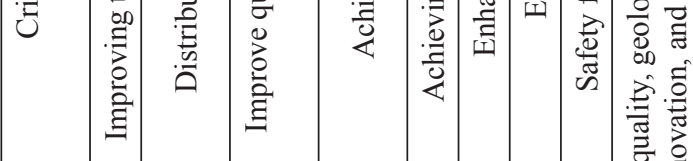

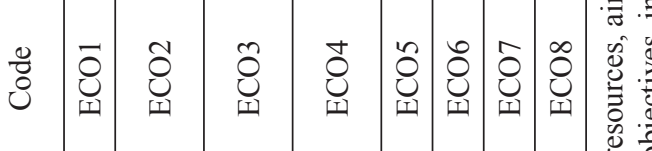

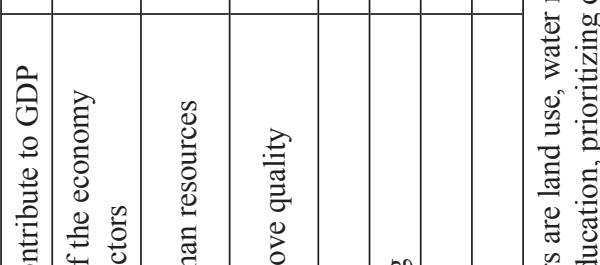

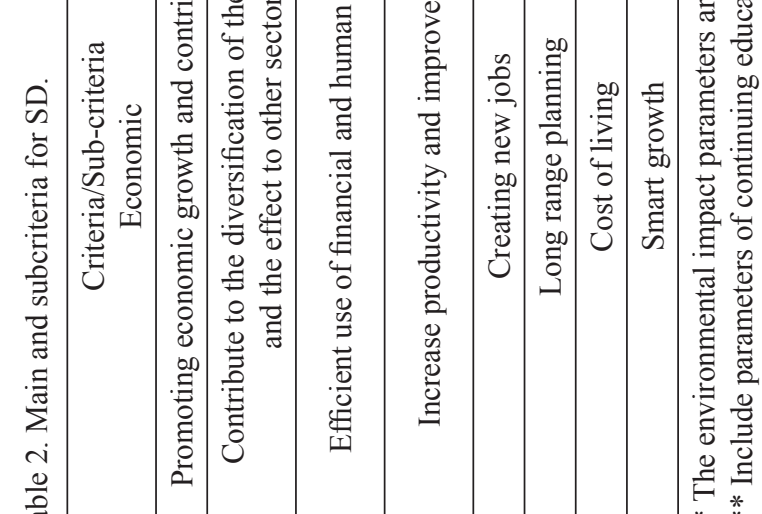


construction industry to attain SD in a specialized manner for KSA.

\section{Population and Sample Size}

The target population for this research was obtained from construction industry companies working in Saudi Arabia. Table 1 lists the construction industry field of applications and the number of companies working in the Kingdom. Various sampling methods are available; however, the stratified sampling technique under nonprobability sampling has been used in this paper. The number of questionnaires collected from each construction industry category is the first number illustrated between the two parentheses in Table 1 for SEM; the second number illustrates the sample taken from each construction industry sector category for AHP. The study was conducted in December 2018 among 100 experts working in 29 construction industry categories in Saudi Arabia. Participation in the survey was completely voluntary. A total of 210 questionnaires were handed out at the beginning of the study and were subsequently collected. A total of 150 questionnaires were returned, at least partly completed. A total of 100 data records remained after discarding incomplete questionnaires. The table shows that a sample size of 100 for SEM and a sample size of 166 for AHP were used.

Table 2 lists the subcriteria of the problem. Table shows the 8 economic subcriteria coded ECO1 to ECO8, 8 environmental criteria coded ENV1 to ENV8, and 5 social criteria coded SOC1 to SOC5. To test the model, a survey was conducted to investigate the main and subcriteria of the theoretical model. A sample of
100 interviewees was sampled to determine the most important subcriteria for the main SD with respect to EES criteria. The survey consisted of a questionnaire developed from material discussed and tested previously. The subcriteria for each main criterion are listed in Table 2.

\section{Theoretical SEM Model}

The theoretical framework used in this research is based on the sustainability definitions and concepts that focus not only on the environmental aspect but also on the economic and social aspects. The framework is a development of three interdependent and integrated dimensions within an interactive framework that is precisely characterized by the organization and rationalization of materials [39]. It is decided that the problem has three main criteria that are EES. Furthermore, each criterion has a set of subcriteria. The economic criterion includes ECO1 to ECO8. The environmental criterion includes ENV1 to ENV8. The social criterion includes SOC1 to SOC5. The theoretical SEM model is defined in Fig. 1.

The collected data were analyzed using partial least squares (PLS) [40] modeling to assess the scales' validity and test the hypotheses. This analysis was done using SmartPLS software. PLS is a componentbased structural equation modeling technique that has minimal demands on measurement scales, sample size, and residual distributions [41-44]. We choose PLS because of its minimal requirements regarding sample size and prediction capability [45]. The number of cases is sufficient to detect relationships of a medium effect size with a power of $95 \%(n=100)$. This statistical

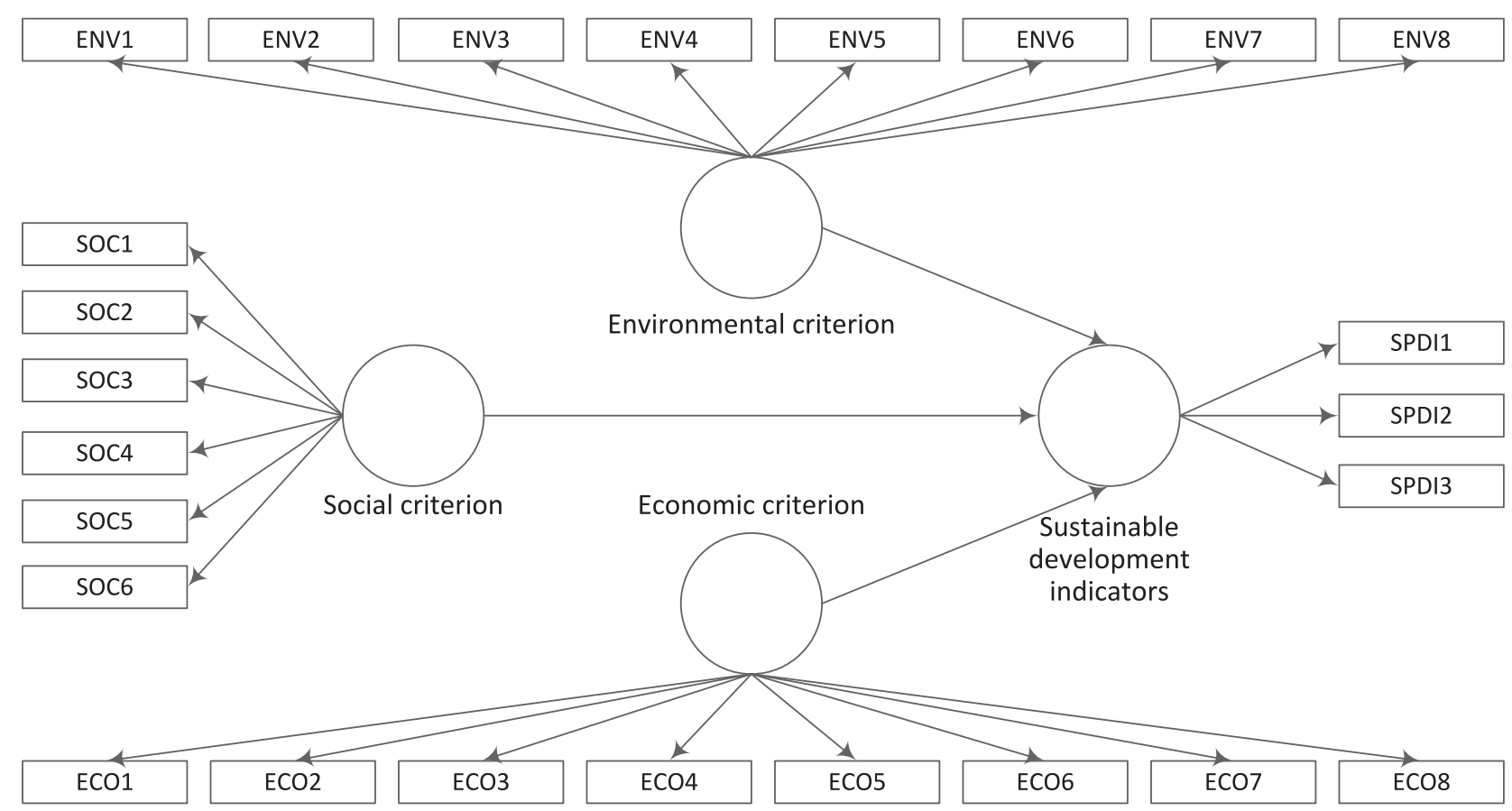

Fig. 1. SmartPLS representation of the initial model. 
power is regarded as sufficient because the hypotheses were previously tested in other contexts. Therefore, it is likely that small effect sizes were discovered. The PLS is a 2-step procedure concerned with building and testing the measurement model and building and testing of a structure model. The first outer measurement model is concerned with measuring the convergent validity by individual item reliability $(>0.700)$, composite reliability $(>0.700$ ), and average variance extracted (AVE $>0.500$ ). In addition, in this model the discriminate reliability was measured in terms of cross loading, and variable correlations are evaluated. The second inner structure model is concerned with the coefficient of determination $\left(\mathrm{R}^{2}\right)$, effect size $\left(\mathrm{f}^{2}\right)$, predictive relevance $\left(\mathrm{q}^{2}\right)$, goodness of fit of the model, and hypotheses testing.

\section{AHP Hierarchy}

The results of SEM analysis were used as an input to the AHP model. The stages proposed by [46, 47] for using the AHP method were as follows. The AHP model will be developed by deleting the non-significant subcriteria from the initial model. There are three main phases in the AHP model methodology: structuring the problem, comparative judgments, and priority analysis.
Fig. 2 depicts the general AHP model for prioritizing investment in the construction industrial sector in KSA. At the top of the hierarchy, Level 1, is the goal of the model's decision-making process. In Level 2, the main criteria directly related to Level 1 are highlighted, and their relative priorities are stipulated. It is possible to observe that, in Level 2, important criteria are considered in the decision-making process. To evaluate the main criteria and to clarify all the criteria, the decision makers considered some of the more important criteria. Then, in Level 3, the subcriteria were used as a direct reference for evaluating the decision alternatives as described, remembering that these subcriteria are pairwise numerical comparisons. It is important to note that the subcriteria in Level 3 will serve as a foundation for evaluating each of the 29 decision alternatives, as presented in Fig. 2, which, in turn, presents the set of criteria that will help in the decision-making process. Once all the criteria have been considered and presented in the hierarchical tree in a structured manner, in order to achieve the objective proposed in the model it is time for the next phase of the AHP Fig. 3 depicts the adopted modeling procedure in the research. First, the AHP model was developed in Expert Choice software; then, data collection was done for primary and secondary

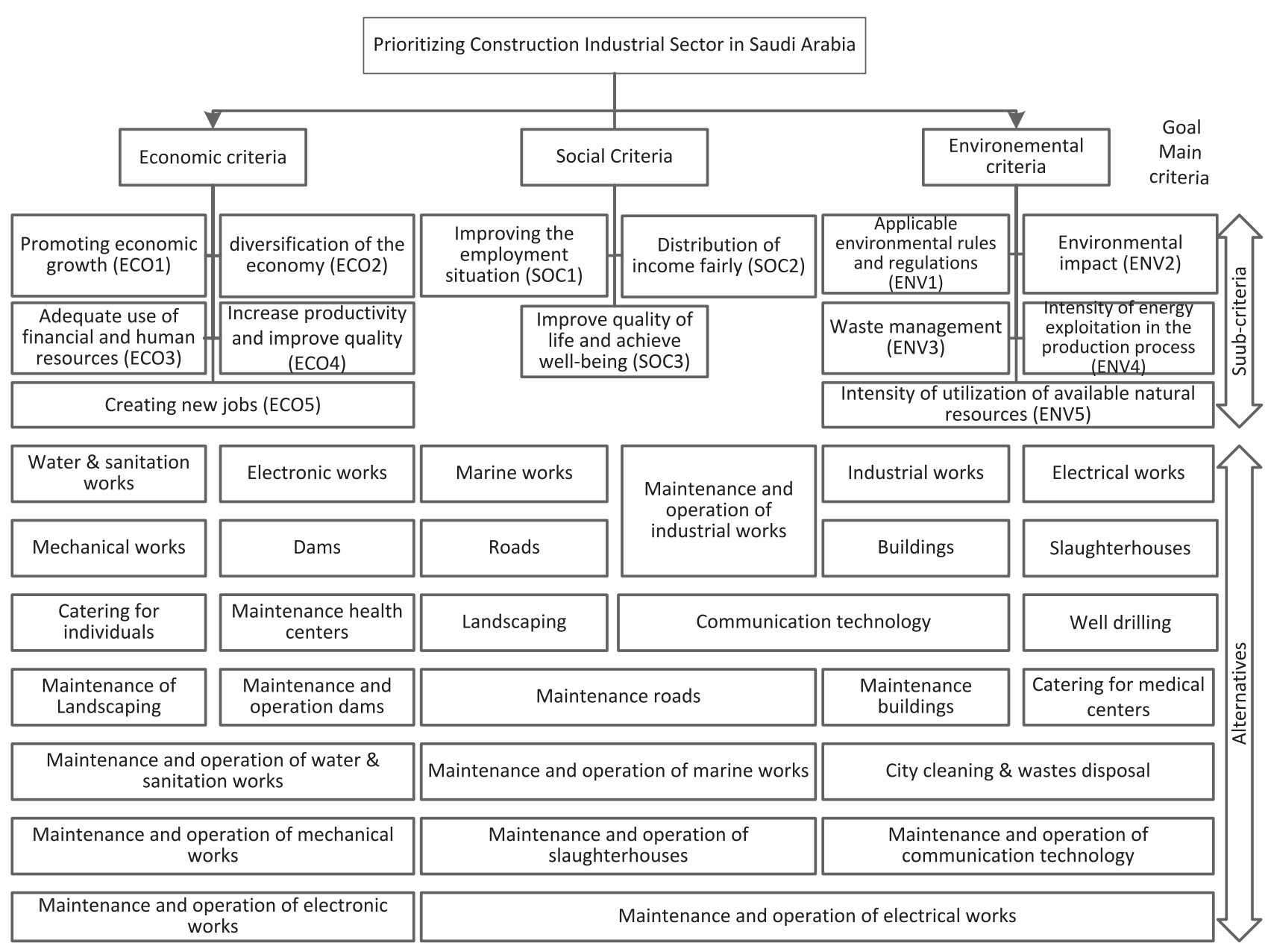

Fig. 2. General AHP model. 


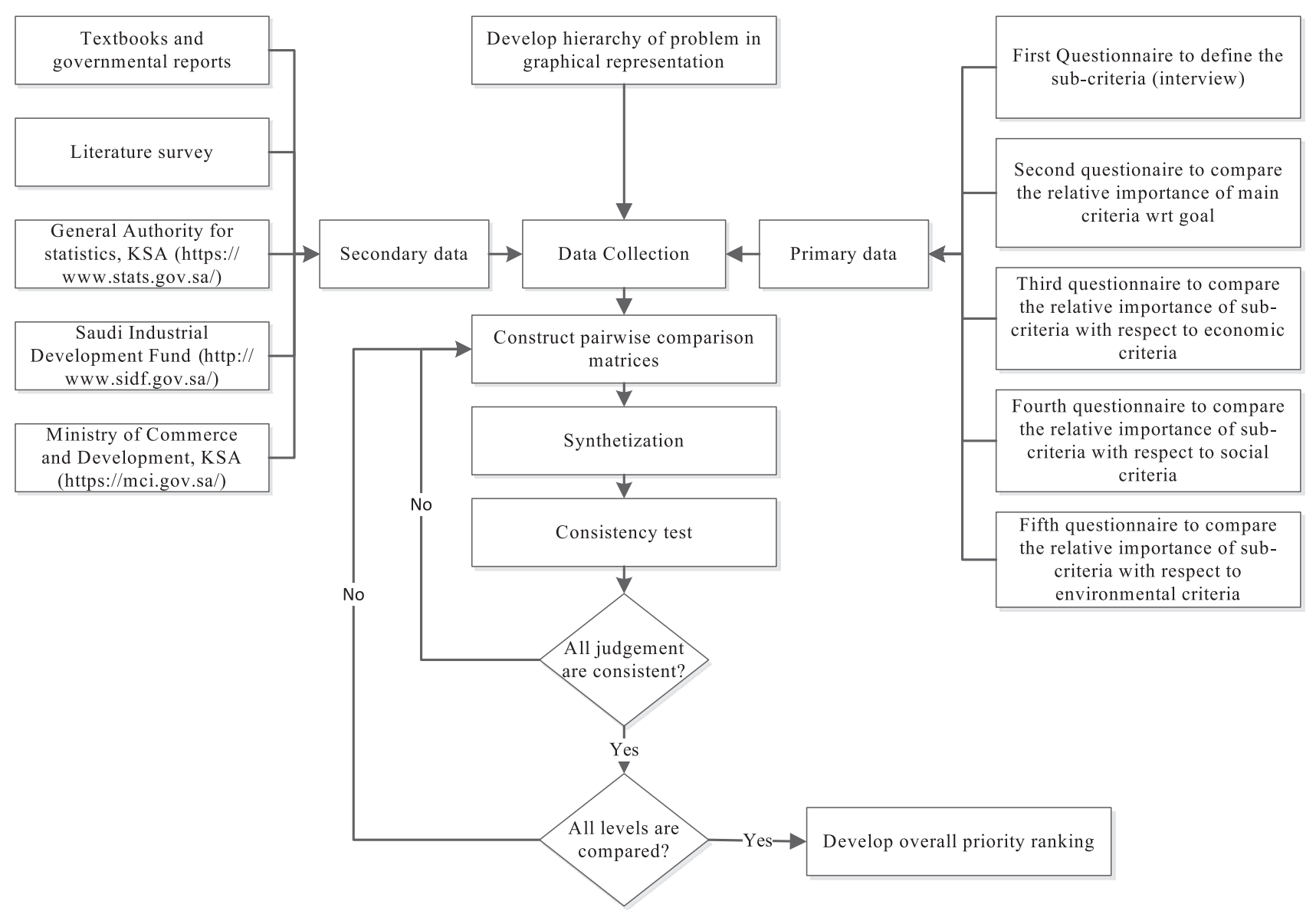

Fig. 3. AHP solution methodology.

data. The primary data were collected using four related questionnaires for comparing the relative importance of the main criteria with respect to the goal, comparing the relative importance of the economic subcriteria with respect to economic criteria, comparing the relative importance of the social subcriteria with respect to social criteria, and comparing the relative importance of the environmental subcriteria with respect to environmental criteria. In addition, the research depends on secondary data available as per governmental reports, a literature survey, and the data available on the electronic website of the Saudi General Authority for Statistics [9], the Saudi Industrial Development Fund [48], and the Ministry of Commerce and Investment [8]. The investment proportion for each construction industry type does not have a model for evaluating the priority of investment to achieve the SD in KSA. Hence, this proportion is determined empirically by construction managers who have a considerable length of service time leading the construction organizations. Thus, the AHP is presented such that it can be used as an efficient method for the decision-making process, identifying the best option among the proposed alternatives. Thus, according to the above, the hierarchical structure of the criteria [49] is presented in Fig. 1.

At each node of the hierarchy, a matrix is designed to collect the pairwise comparisons of the decision-maker.
In this article, the relative importance had been done with respect to the goal with the criteria, and the relative preference was done with respect to the subcriteria. AHP uses a ratio scale, in contrast to methods using interval scales [50], which requires no units in the comparison. The pair judgment scale was used for these comparisons; therefore, the preferences for each element were determined. Having obtained these values, comparison matrixes were generated for the subcriteria; 166 participants were interviewed in order to define the following pairwise comparisons:

- Pairwise comparison matrix for the main criteria with respect to the goal (one questionnaire).

- Pairwise comparison matrix for the subcriteria with respect to the economic criteria (one questionnaire).

- Pairwise comparison matrix for the subcriteria with respect to the social criteria (one questionnaire).

- Pairwise comparison matrix for the subcriteria with respect to the environmental criteria (one questionnaire).

- Pairwise comparison for alternatives with respect to the subcriteria (15 questionnaires, 5 questionnaires for each subcriterion).

One of the AHP's strengths is the possibility of evaluating quantitative as well as qualitative criteria and alternatives on the same preference scale of nine levels. These scales can be numerical $(1,2 \ldots 9)$, verbal 
Table 3. Summary of items and results of measurement model convergent validity

\begin{tabular}{|c|c|c|c|c|c|}
\hline \multirow{3}{*}{ Construct } & \multirow{2}{*}{ Item } & \multicolumn{4}{|c|}{ Results of convergent validity } \\
\hline & & \multicolumn{4}{|c|}{ Final model } \\
\hline & Code & Loading & $\mathrm{CR}$ & $\alpha$ & AVE \\
\hline \multirow{5}{*}{$\begin{array}{c}\text { Economic } \\
\text { criteria }\end{array}$} & ECO1 & 0.709 & \multirow{5}{*}{0.902} & \multirow{5}{*}{0.864} & \multirow{5}{*}{0.649} \\
\hline & $\mathrm{ECO} 2$ & 0.783 & & & \\
\hline & $\mathrm{ECO} 3$ & 0.822 & & & \\
\hline & $\mathrm{ECO} 4$ & 0.857 & & & \\
\hline & $\mathrm{ECO} 5$ & 0.847 & & & \\
\hline \multirow{5}{*}{$\begin{array}{c}\text { Environmental } \\
\text { criteria }\end{array}$} & ENV1 & 0.749 & \multirow{5}{*}{0.856} & \multirow{5}{*}{0.793} & \multirow{5}{*}{0.542} \\
\hline & ENV2 & 0.721 & & & \\
\hline & ENV3 & 0.760 & & & \\
\hline & ENV4 & 0.718 & & & \\
\hline & ENV5 & 0.732 & & & \\
\hline \multirow{3}{*}{ Social criteria } & SOC1 & 0.767 & \multirow{3}{*}{0.835} & \multirow{3}{*}{0.703} & \multirow{3}{*}{0.628} \\
\hline & $\mathrm{SOC} 2$ & 0.772 & & & \\
\hline & SOC3 & 0.836 & & & \\
\hline \multirow{3}{*}{ SDPIs } & SPDI1 & 0.761 & \multirow{3}{*}{0.825} & \multirow{3}{*}{0.701} & \multirow{3}{*}{0.612} \\
\hline & SPDI2 & 0.738 & & & \\
\hline & SPDI3 & 0.844 & & & \\
\hline
\end{tabular}

(extreme, very strong, strong, and equal) or graphical in a chart, as available input alternatives in Expert Choice software. The eigenvalue method was used as a priority derivation method in the model [46, 47]. An inconsistency ratio of $10 \%$ was adopted in this research. The additive aggregation was used in the Expert Choice distributive mode. Expert Choice allows different sensitivity analyses, where the main difference is the various graphical representations.

\section{Results and Discussion}

Since the research used an integrated methodology of SEM and AHP and these methods were applied sequentially, each with a different statistical sample and analysis, the results of the application of the two methods will be presented in this section.

\section{SEM Sample Characteristics and Results}

\section{SEM Sample Characteristics}

A questionnaire was developed that contains ECO1 to ECO8, ENV1 to ENV8, and SOC1-SOC5 with sustainability performance indicators (SPDI1, SPDI2, and SPDI3). The participants rated a particular criterion based on the effect of the indicator, and to complete the
Table 4. Cross loadings - discriminate validity.

\begin{tabular}{|l|c|c|c|c|}
\hline \multirow{2}{*}{ Item } & \multicolumn{3}{|c|}{ Latent variable } \\
\cline { 2 - 5 } & $\begin{array}{c}\text { Economic } \\
\text { criterion }\end{array}$ & $\begin{array}{c}\text { Environ- } \\
\text { mental } \\
\text { criterion }\end{array}$ & $\begin{array}{c}\text { Social } \\
\text { criterion }\end{array}$ & SDPIs \\
\hline ECO1 & $\mathbf{0 . 7 0 9}$ & 0.584 & 0.426 & 0.407 \\
\hline ECO2 & $\mathbf{0 . 7 8 3}$ & 0.526 & 0.490 & 0.642 \\
\hline ECO3 & $\mathbf{0 . 8 2 2}$ & 0.527 & 0.540 & 0.560 \\
\hline ECO4 & $\mathbf{0 . 8 5 7}$ & 0.560 & 0.404 & 0.578 \\
\hline ECO5 & $\mathbf{0 . 8 4 7}$ & 0.493 & 0.419 & 0.488 \\
\hline ENV1 & 0.424 & $\mathbf{0 . 7 4 9}$ & 0.606 & 0.434 \\
\hline ENV2 & 0.521 & $\mathbf{0 . 7 2 1}$ & 0.394 & 0.530 \\
\hline ENV3 & 0.445 & $\mathbf{0 . 7 6 0}$ & 0.514 & 0.426 \\
\hline ENV4 & 0.462 & $\mathbf{0 . 7 1 8}$ & 0.457 & 0.399 \\
\hline ENV5 & 0.553 & $\mathbf{0 . 7 3 2}$ & 0.501 & 0.609 \\
\hline SOC1 & 0.441 & 0.588 & $\mathbf{0 . 7 6 7}$ & 0.491 \\
\hline SOC2 & 0.452 & 0.465 & $\mathbf{0 . 7 7 2}$ & 0.457 \\
\hline SOC3 & 0.459 & 0.531 & $\mathbf{0 . 8 3 6}$ & 0.511 \\
\hline SPDI1 & 0.449 & 0.449 & 0.470 & $\mathbf{0 . 7 6 1}$ \\
\hline SPDI2 & 0.451 & 0.414 & 0.444 & $\mathbf{0 . 7 3 8}$ \\
\hline SPDI3 & 0.655 & 0.665 & 0.524 & $\mathbf{0 . 8 4 4}$ \\
\hline
\end{tabular}

survey analysis, the elements of the questionnaire were rated on a Likert scale. SmartPLS was used to model the collected data as a structure equation model to assess the measurement and structural models. To define the main and subcriteria for the problem, a sample of 100 participants from all construction industry employees, including top and middle level managers and specialist engineers who had more than 10 years of experience. A total of $100 \%$ of participants in the SEM questionnaire were male due to the special nature of Saudi society. Only $52 \%$ of the members of the sample were higher diploma holders; some were factory owners and members of industrial associations. Of the sample, $41.1 \%$ of the sample had a bachelor's degree qualification, and $18.9 \%$ of the sample had master's and higher degrees. In addition, $1 \%$ of the respondents had less than a year experience; $22.5 \%$ of the sample had 5 to 10 years of experience, and $72.5 \%$ of the respondents had more than 10 years of experience. Of the sample, $45.0 \%$ of respondents worked in the public sector and $22.5 \%$ of the sample worked in the private sector. Furthermore, 7.5\% worked in international institutions, while the percentage of sample members who worked in educational institutions was $25.0 \%$.

\section{Measurement and Structural Model Assessment}

The measurement assessment can be achieved by evaluating the indicator reliability $>0.500$ [51], Cronbach's alpha, $\alpha>0.700$ [51], convergent reliability, internal consistency [52], and discriminant validity. The parameter setting for SmartPLS was a path for a 


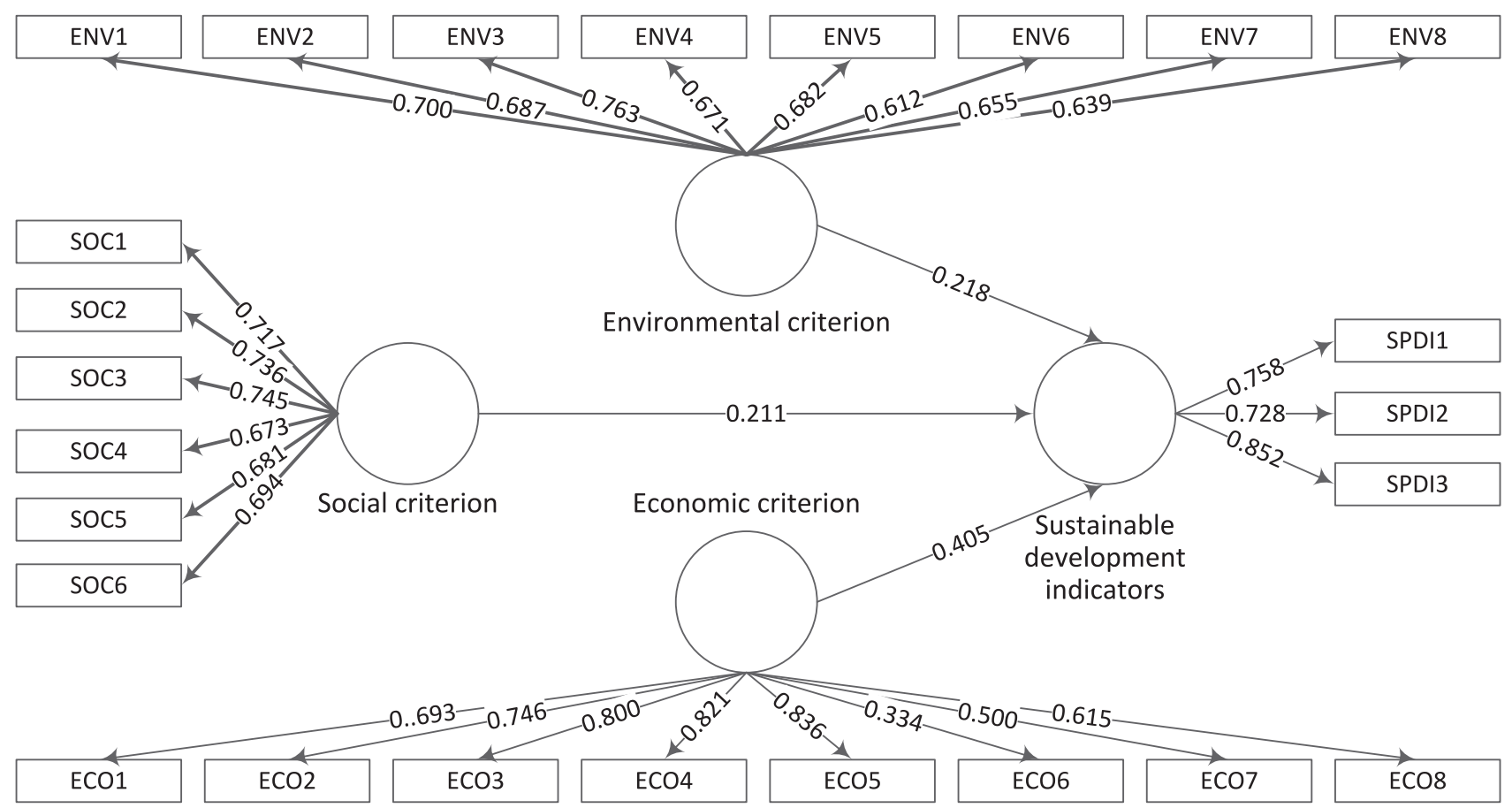

Fig. 4. SmartPLS representation of the initial model.

weighting scheme, 300 maximum iterations, and $10^{-7}$ as a stopping criterion. For analyzing the initial model depicted in Fig. 1, SmartPLS was run with sitting parameters defined previously; the results are shown in Fig. 4. The composite reliability of constructs is shown in Fig. 4, indicating that the composite reliability of all constructs was above the 0.700 threshold value, which demonstrates high levels of internal consistency and reliability for constructs except for factors ECO6,
ECO7, ECO8, ENV6, ENV7, ENV8, SOC4, SOC5, and SOC6, which achieved loading $<0.700$. These factors will be deleted for further development of the final model. By deleting the factors one by one with outer loadings $<0.700$ from the initial model, a new model is obtained, which should be investigated as shown in Fig. 5. The figure shows that the path coefficients for EES constructs are $0.368,0.279$, and 0.220 , respectively, which reflect the causality effect of constructs. Table 3

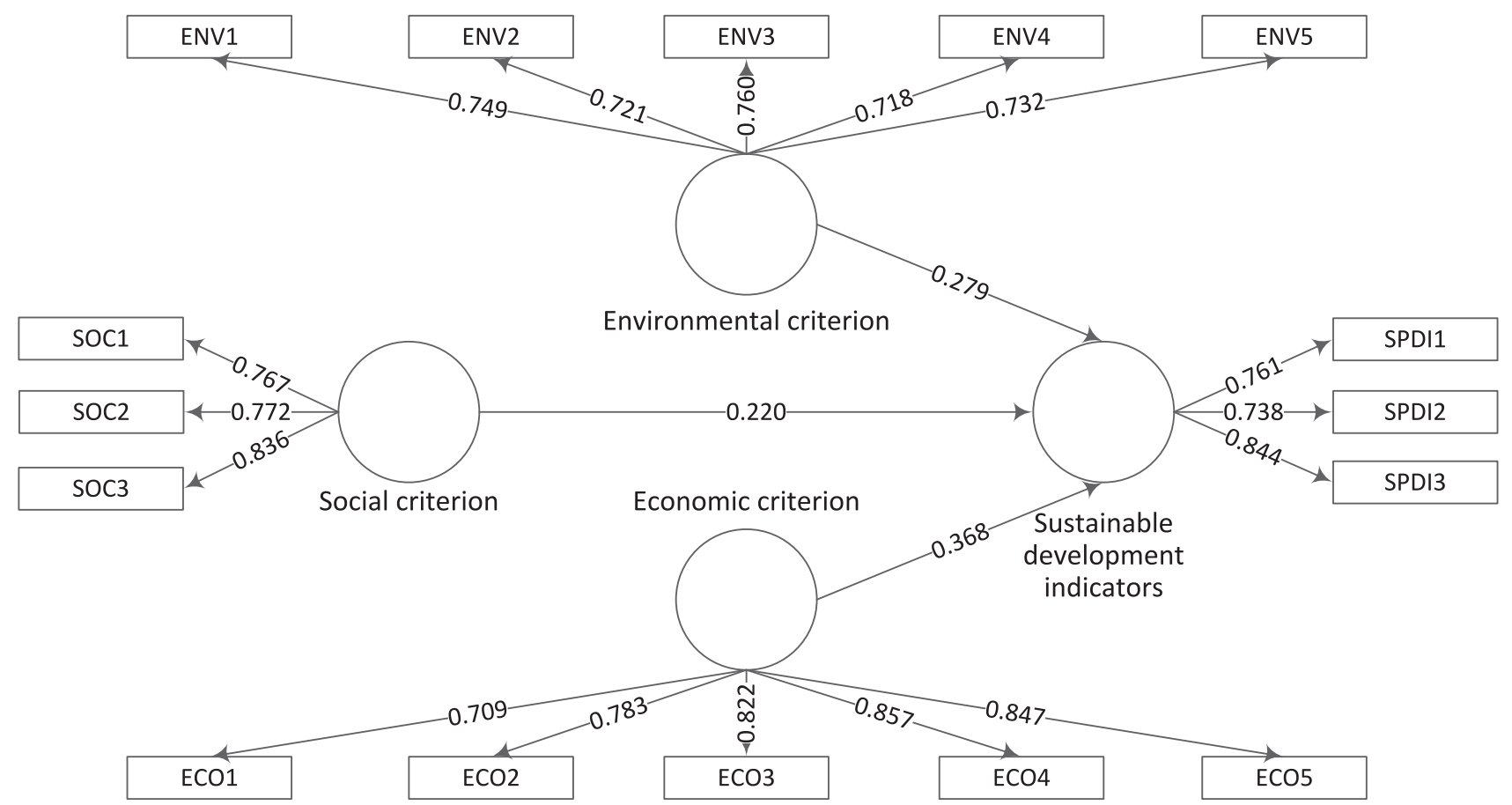

Fig. 5. SmartPLS representation of the final model. 
Table 5. FL criterion and HTMT ratio - discriminate validity.

\begin{tabular}{|c|c|c|c|c|c|c|c|c|}
\hline \multirow{2}{*}{ Latent variable } & \multicolumn{2}{|c|}{ Economic } & \multicolumn{2}{c|}{ Environmental } & \multicolumn{2}{c|}{ Social } & \multicolumn{2}{c|}{ SDPIs } \\
\cline { 2 - 9 } & FL & HTMT & FL & HTMT & FL & HTMT & FL & HTMT \\
\hline Economic & 0.805 & & & & & & & \\
\hline Environmental & 0.664 & 0.792 & 0.736 & & & & & \\
\hline Social & 0.569 & 0.727 & 0.668 & 0.894 & 0.792 & & & \\
\hline SDPIs & 0.678 & 0.840 & 0.670 & 0.855 & 0.615 & 0.879 & 0.782 & \\
\hline
\end{tabular}

Table 6. Hypothesis testing: bootstrapping direct effect results.

\begin{tabular}{|c|c|c|c|c|c|c|c|c|c|}
\hline Hypothesis & Relationship & $\begin{array}{c}\text { Std. } \\
\text { Beta }\end{array}$ & $\begin{array}{c}\text { Std. } \\
\text { Error }\end{array}$ & T-value & Decision & $\mathrm{f}^{2}$ & $\mathrm{q}^{2}$ & $\begin{array}{c}95 \% \\
\text { CI LL }\end{array}$ & $\begin{array}{c}95 \% \\
\text { CI UL }\end{array}$ \\
\hline $\mathrm{H}_{1}$ & Economic criteria $\rightarrow \mathrm{SD}$ & 0.369 & 0.085 & $4.346^{* *}$ & Supported & 0.170 & 0.055 & 0.228 & 0.502 \\
\hline $\mathrm{H}_{2}$ & Environment criterion $\rightarrow \mathrm{SD}$ & 0.278 & 0.103 & $2.713^{* *}$ & Supported & 0.084 & 0.014 & 0.111 & 0.446 \\
\hline $\mathrm{H}_{3}$ & Social criterion $\rightarrow \mathrm{SD}$ & 0.224 & 0.095 & $2.309^{* *}$ & Supported & 0.051 & 0.016 & 0.073 & 0.383 \\
\hline
\end{tabular}

$* * \mathrm{P}<0.010, * \mathrm{P}<0.050 \quad \mathrm{R}^{2}(\mathrm{SD}=0.571)$

Effect size impact indicator are according to [49], $\mathrm{f}^{2}$ values:0.350 (large), 0.150 (medium), and 0.020 (small) $\mathrm{q}^{2}(\mathrm{SD}=0.314)$, predictive relevance $\left(\mathrm{q}^{2}\right)$ of predictor exogenous latent variables as according to [50], q2 values: 0.350 (large), 0.150 (medium), and 0.020 (small)

measures the convergent validity of the final model in terms of construct outer loadings in column 4, composite reliability in column 5, and Average Variance Extracted (AVE) in column 6. The table shows outer loadings $>0.700, \alpha>0.700, \mathrm{CR}>0.700$, and AVE $>0.500$. Table 4 shows that all indicators' individual loadings were found to be higher than their respective cross-loadings in order to validate the discriminant validity of the model.

Table 5 lists the values of the Fornell-Larcker criterion (FL) [53] AVE > squared correlations and a Heterotrait-Monotrait (HTMT) ratio of correlation $<0.9$ [44], as measured for the discriminant validity for constructs. The hypothesis developed for this study was tested by running a bootstrapping procedure with a resample of 5000, as suggested by [44], Bias-corrected and accelerated bootstrap two-tailed with a significance level of 0.050 , with selection of the individual sign changes option. Table 6 depicts that the relationship between EES criteria to SD is supported by $\mathrm{H}_{1}, \mathrm{H}_{2}$, and $\mathrm{H}_{3}$ at the 0.010 level of significance. The coefficient of determination for the multivariate regression model $\left(\mathrm{R}^{2}\right)$ is equal to 0.571 , indicating a good fit, with the effect size $\left(\mathrm{f}^{2}\right)$ being medium for $\mathrm{H}_{1}, \mathrm{H}_{2}$, and $\mathrm{H}_{3}$. The predictive relevance $\left(\mathrm{q}^{2}\right)$ is medium, small, and small.

\section{AHP Sample Characteristics and Results}

\section{Sample Size}

$100 \%$ of participants in the first questionnaire were male (due to the special nature of Saudi society). Only $52 \%$ of the members of the sample were diploma holders. Some of the sample were factory owners and members of industrial associations; $41.1 \%$ of the sample had a bachelor's degree qualification, and $18.9 \%$ of the sample had higher degrees. In addition, $1 \%$ of the respondents had less than a year of experience; $22.5 \%$ of the sample had 5 to 10 years of experience, and $72.5 \%$ of the respondents had more than 10 years of experience. A total of $45.0 \%$ of the sample of respondents worked in the public sector; $22.5 \%$ of the sample worked in the private sector. Another $7.5 \%$ worked in international institutions, while the percentage of sample members who worked in educational institutions was $25.0 \%$.

\section{Comparative Judgement}

For the next phase of the AHP model, paired comparisons were made between the subcriteria on the same level. The pair judgment scale was used for these comparisons, and the preferences for each element were determined. Having obtained these values, comparison matrixes were generated for the criteria as shown in Fig. 6, with an inconsistency ratio of 0.070 as given by Expert Choice. Figs 6 to 9 are the questionnaires sent to the participants. A number rating was framed as $1=$ equal, $2=$ moderate, $5=$ strong, $7=$ very strong, and 9 = extreme and applied for evaluating the relative importance of EES criteria. The scale is graded based on the benefit priority level (either as a blue color on the left side benefit criteria level or a red color on the right-side benefit criteria level), and the numerical value is assigned. Figs 7 to 9 show the ratings for the questionnaire comparing the relative importance of subcriteria of the EES dimension of SD. Fig. 10 shows the survey questions of the questionnaire to rate the relative importance of ECO1 with respect to alternative 


\begin{tabular}{|c|c|c|c|c|c|c|c|c|c|c|c|c|c|c|c|c|c|c|c|}
\hline 1 & Economic & 9 & 8 & 7 & 6 & 5 & 4 & 3 & 2 & 1 & 2 & 3 & 4 & 5 & 6 & 7 & 8 & 9 & Environmental \\
\hline 2 & Economic & 9 & 8 & 7 & 6 & 5 & 4 & 3 & 2 & 1 & 2 & 3 & 4 & 5 & 6 & 7 & 8 & 9 & Social \\
\hline 3 & Environmental & 9 & 8 & 7 & 6 & 5 & 4 & 3 & 2 & 1 & 2 & 3 & 4 & 5 & 6 & 7 & 8 & 9 & Social \\
\hline
\end{tabular}

Fig. 6. Comparison of the relative importance of the EES criteria with the goal.

\begin{tabular}{|c|c|c|c|c|c|c|c|c|c|c|c|c|c|c|c|c|c|c|c|}
\hline 1 & ECO1 & 9 & 8 & 7 & 6 & 5 & 4 & 3 & 2 & 1 & 2 & 3 & 4 & 5 & 6 & 7 & 8 & 9 & ECO2 \\
\hline 2 & ECO1 & 9 & 8 & 7 & 6 & 5 & 4 & 3 & 2 & 1 & 2 & 3 & 4 & 5 & 6 & 7 & 8 & 9 & ECO3 \\
\hline 3 & ECO1 & 9 & 8 & 7 & 6 & 5 & 4 & 3 & 2 & 1 & 2 & 3 & 4 & 5 & 6 & 7 & 8 & 9 & ECO4 \\
\hline 4 & ECO1 & 9 & 8 & 7 & 6 & 5 & 4 & 3 & 2 & 1 & 2 & 3 & 4 & 5 & 6 & 7 & 8 & 9 & ECO5 \\
\hline 5 & ECO2 & 9 & 8 & 7 & 6 & 5 & 4 & 3 & 2 & 1 & 2 & 3 & 4 & 5 & 6 & 7 & 8 & 9 & ECO3 \\
\hline 6 & ECO2 & 9 & 8 & 7 & 6 & 5 & 4 & 3 & 2 & 1 & 2 & 3 & 4 & 5 & 6 & 7 & 8 & 9 & ECO4 \\
\hline 7 & ECO2 & 9 & 8 & 7 & 6 & 5 & 4 & 3 & 2 & 1 & 2 & 3 & 4 & 5 & 6 & 7 & 8 & 9 & ECO5 \\
\hline 8 & ECO3 & 9 & 8 & 7 & 6 & 5 & 4 & 3 & 2 & 1 & 2 & 3 & 4 & 5 & 6 & 7 & 8 & 9 & ECO4 \\
\hline 9 & ECO3 & 9 & 8 & 7 & 6 & 5 & 4 & 3 & 2 & 1 & 2 & 3 & 4 & 5 & 6 & 7 & 8 & 9 & ECO5 \\
\hline 10 & ECO4 & 9 & 8 & 7 & 6 & 5 & 4 & 3 & 2 & 1 & 2 & 3 & 4 & 5 & 6 & 7 & 8 & 9 & ECO5 \\
\hline
\end{tabular}

Fig. 7. Comparison of the relative importance of the subcriteria of economic criteria.

\begin{tabular}{|c|l|l|l|l|l|l|l|l|l|l|l|l|l|l|l|l|l|l|l|}
\hline 1 & ENV1 & 9 & 8 & 7 & 6 & 5 & 4 & 3 & 2 & 1 & 2 & 3 & 4 & 5 & 6 & 7 & 8 & 9 & ENV2 \\
\hline 2 & ENV1 & 9 & 8 & 7 & 6 & 5 & 4 & 3 & 2 & 1 & 2 & 3 & 4 & 5 & 6 & 7 & 8 & 9 & ENV3 \\
\hline 3 & ENV1 & 9 & 8 & 7 & 6 & 5 & 4 & 3 & 2 & 1 & 2 & 3 & 4 & 5 & 6 & 7 & 8 & 9 & ENV4 \\
\hline 4 & ENV1 & 9 & 8 & 7 & 6 & 5 & 4 & 3 & 2 & 1 & 2 & 3 & 4 & 5 & 6 & 7 & 8 & 9 & ENV5 \\
\hline 5 & ENV2 & 9 & 8 & 7 & 6 & 5 & 4 & 3 & 2 & 1 & 2 & 3 & 4 & 5 & 6 & 7 & 8 & 9 & ENV3 \\
\hline 6 & ENV2 & 9 & 8 & 7 & 6 & 5 & 4 & 3 & 2 & 1 & 2 & 3 & 4 & 5 & 6 & 7 & 8 & 9 & ENV4 \\
\hline 7 & ENV2 & 9 & 8 & 7 & 6 & 5 & 4 & 3 & 2 & 1 & 2 & 3 & 4 & 5 & 6 & 7 & 8 & 9 & ENV5 \\
\hline 8 & ENV3 & 9 & 8 & 7 & 6 & 5 & 4 & 3 & 2 & 1 & 2 & 3 & 4 & 5 & 6 & 7 & 8 & 9 & ENV4 \\
\hline 9 & ENV3 & 9 & 8 & 7 & 6 & 5 & 4 & 3 & 2 & 1 & 2 & 3 & 4 & 5 & 6 & 7 & 8 & 9 & ENV5 \\
\hline 10 & ENV4 & 9 & 8 & 7 & 6 & 5 & 4 & 3 & 2 & 1 & 2 & 3 & 4 & 5 & 6 & 7 & 8 & 9 & ENV5 \\
\hline
\end{tabular}

Fig. 8. Comparison of the relative importance of the subcriteria of environmental criteria.

\begin{tabular}{|l|l|l|l|l|l|l|l|l|l|l|l|l|l|l|l|l|l|l|l|}
\hline 1 & SOC1 & 9 & 8 & 7 & 6 & 5 & 4 & 3 & 2 & 1 & 2 & 3 & 4 & 5 & 6 & 7 & 8 & 9 & SOC2 \\
\hline 2 & SOC1 & 9 & 8 & 7 & 6 & 5 & 4 & 3 & 2 & 1 & 2 & 3 & 4 & 5 & 6 & 7 & 8 & 9 & SOC3 \\
\hline 3 & SOC2 & 9 & 8 & 7 & 6 & 5 & 4 & 3 & 2 & 1 & 2 & 3 & 4 & 5 & 6 & 7 & 8 & 9 & SOC3 \\
\hline
\end{tabular}

Fig. 9 Comparison of the relative importance of the subcriteria of social criteria.

combinations (406 combinations). Even the 406 EES subcriteria combinations for evaluating the questionnaire expose the SD.

\section{AHP Results}

Expert choice software automatically calculates the consistency ratio for judgements to ensure that it will not exceed $10 \%$ according to AHP theory [46, 47].

\section{Comparison of Criteria Results}

Pairwise comparison of criteria: Fig. 11 shows that economic criteria are the most important criteria for the participants with a weight of 0.614 , followed by environmental criteria with a weight of 0.268 , and social with a weight of 0.117 . The inconsistency ratio of 0.070 is considered "acceptable" to continue the AHP analysis [46]. The lower priority of the social 


\begin{tabular}{|c|c|c|c|c|c|c|c|c|c|c|c|c|c|c|c|c|c|c|c|}
\hline 1 & Water \& sanitation works & 9 & 8 & 7 & 6 & 5 & 4 & 3 & 2 & 1 & 2 & 3 & 4 & 5 & 6 & 7 & 8 & 9 & Electronic works \\
\hline 2 & Water \& sanitation works & 9 & 8 & 7 & 6 & 5 & 4 & 3 & 2 & 1 & 2 & 3 & 4 & 5 & 6 & 7 & 8 & 9 & Marine works \\
\hline 3 & Water \& sanitation works & 9 & 8 & 7 & 6 & 5 & 4 & 3 & 2 & 1 & 2 & 3 & 4 & 5 & 6 & 7 & 8 & 9 & Industrial works \\
\hline 4 & Water \& sanitation works & 9 & 8 & 7 & 6 & 5 & 4 & 3 & 2 & 1 & 2 & 3 & 4 & 5 & 6 & 7 & 8 & 9 & Electrical works \\
\hline 5 & Water \& sanitation works & 9 & 8 & 7 & 6 & 5 & 4 & 3 & 2 & 1 & 2 & 3 & 4 & 5 & 6 & 7 & 8 & 9 & Mechanical works \\
\hline 6 & Water \& sanitation works & 9 & 8 & 7 & 6 & 5 & 4 & 3 & 2 & 1 & 2 & 3 & 4 & 5 & 6 & 7 & 8 & 9 & Dams \\
\hline 7 & Water \& sanitation works & 9 & 8 & 7 & 6 & 5 & 4 & 3 & 2 & 1 & 2 & 3 & 4 & 5 & 6 & 7 & 8 & 9 & Roads \\
\hline 8 & Water \& sanitation works & 9 & 8 & 7 & 6 & 5 & 4 & 3 & 2 & 1 & 2 & 3 & 4 & 5 & 6 & 7 & 8 & 9 & Buildings \\
\hline 9 & Water \& sanitation works & 9 & 8 & 7 & 6 & 5 & 4 & 3 & 2 & 1 & 2 & 3 & 4 & 5 & 6 & 7 & 8 & 9 & Slaughterhouses \\
\hline.. & .. &. &. &. &. &. &. &. &. &. &. &. &. &. &. &. &. &. &.. \\
\hline 404 & $\begin{array}{c}\text { Maintenance and operation of } \\
\text { slaughterhouses }\end{array}$ & 9 & 8 & 7 & 6 & 5 & 4 & 3 & 2 & 1 & 2 & 3 & 4 & 5 & 6 & 7 & 8 & 9 & Maintenance and operation of \\
\hline 405 & $\begin{array}{c}\text { Maintenance and operation of } \\
\text { slaughterhouses }\end{array}$ & 9 & 8 & 7 & 6 & 5 & 4 & 3 & 2 & 1 & 2 & 3 & 4 & 5 & 6 & 7 & 8 & 9 & City cleaning \& wastes disposal \\
\hline 406 & $\begin{array}{c}\text { Maintenance and operation of } \\
\text { slaughterhouses }\end{array}$ & 9 & 8 & 7 & 6 & 5 & 4 & 3 & 2 & 1 & 2 & 3 & 4 & 5 & 6 & 7 & 8 & 9 & City cleaning \& wastes disposal \\
\hline
\end{tabular}

Fig. 10. Comparing the relative importance of alternatives combinations relative to ECO1.

criteria can be explained by the weak correlation of its subcriteria with the economic and environmental subcriteria. The stability ratio for the comparison is 0.070 , which is less than 0.100 (the permissible ratio according to AHP theory) [46, 47]. Fig. 11 illustrates the pairwise comparison results for the main criteria using Expert Choice.

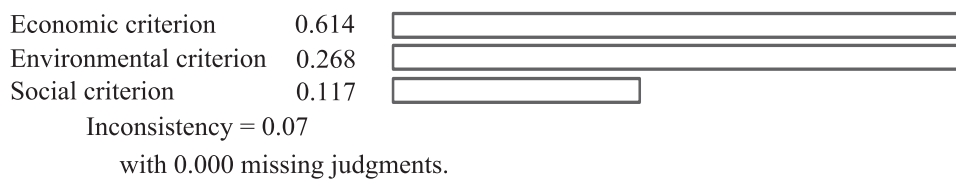

Fig. 11. Pairwise comparison results for the main criteria using Expert Choice.

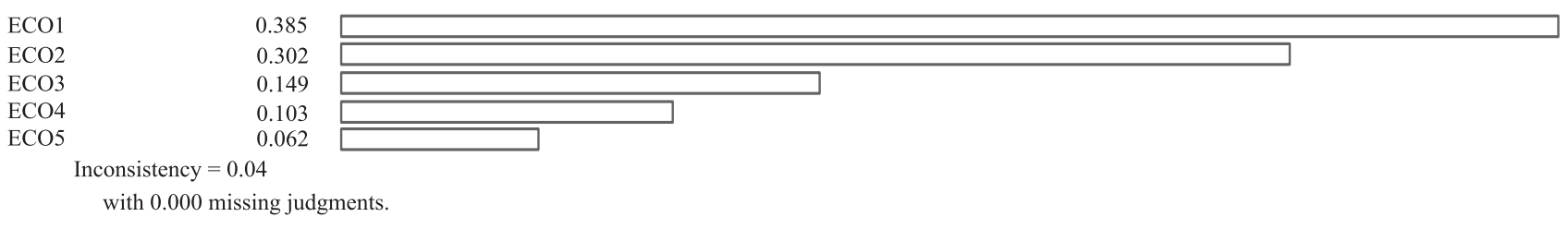

Fig. 12. Pairwise comparison results for economic subcriteria using Expert Choice.

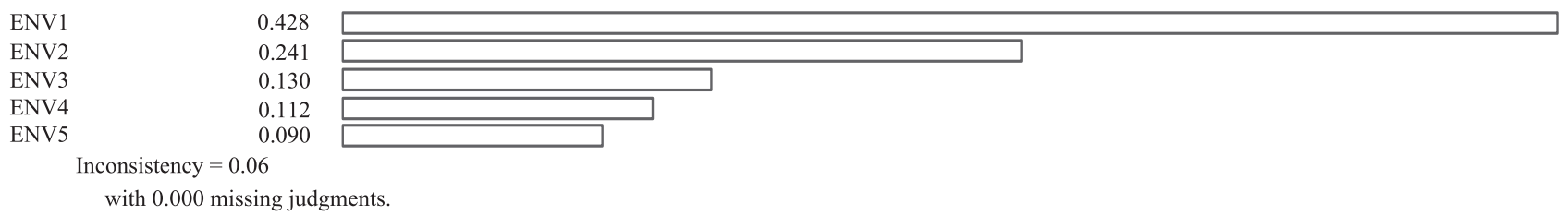

Fig. 13. Pairwise comparison results for environmental subcriteria "ECO1" using Expert Choice.

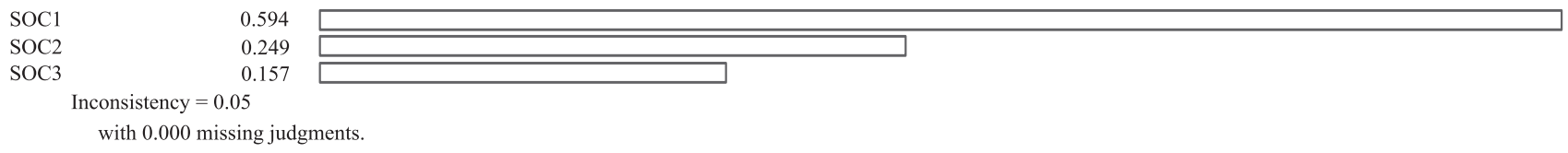

Fig. 14. Pairwise comparison results for social subcriteria using Expert Choice. 


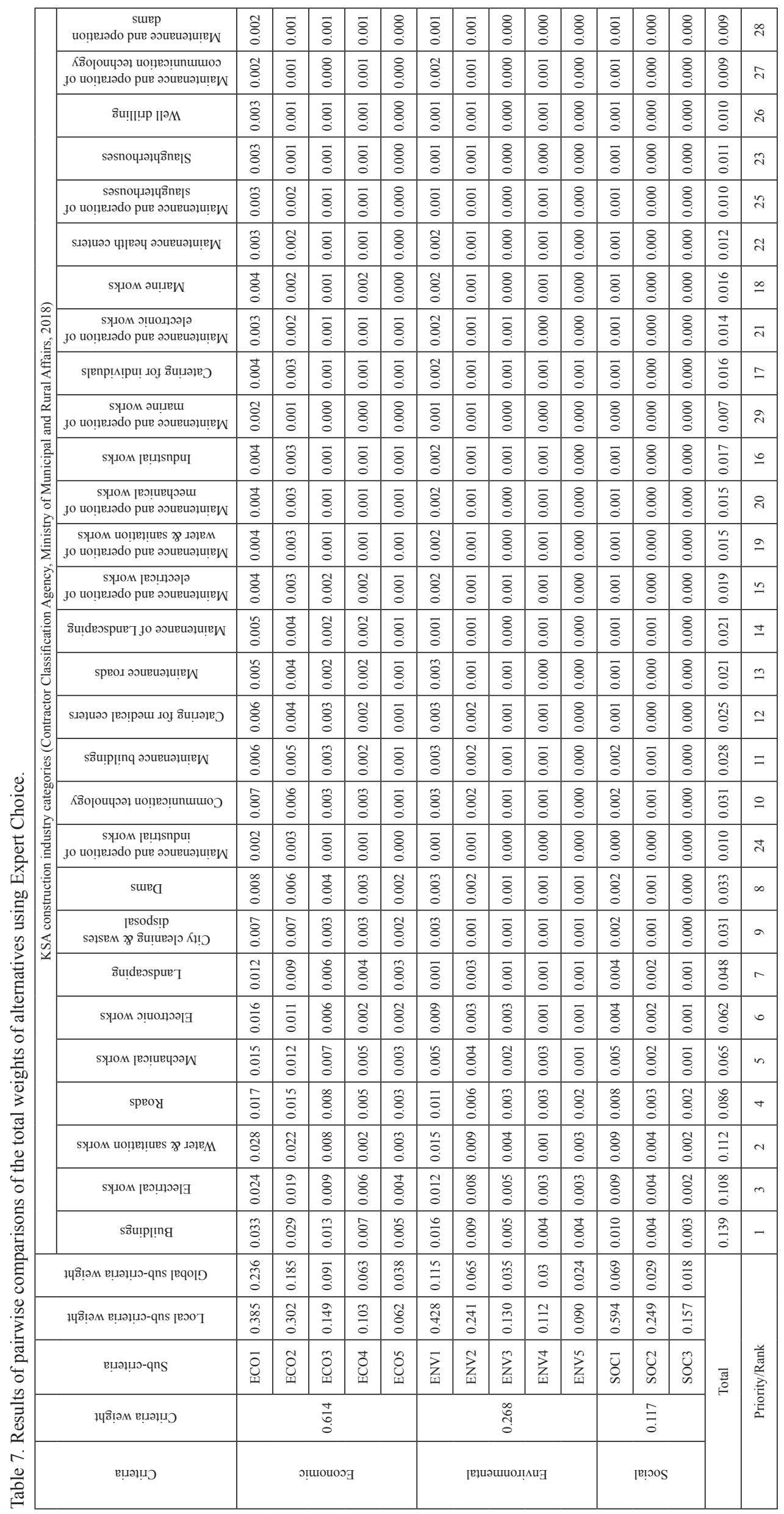




\section{Comparison of Subcriteria Results}

Pairwise comparisons of subeconomic criteria: As shown in Fig. 12, the subeconomic criterion that has the highest importance among the others is "Promoting economic growth and contributing to gross domestic product" at $38.5 \%$, accompanied by "Contribute to the diversification of economy and effects on other sectors" at $30.2 \%$, followed by $14.9 \%$ for "Efficient use of financial and human resources", $10.3 \%$ for "Increase productivity and improve quality", and 6.2\% for "Creating new jobs". The stability ratio for the comparison is 0.040 , which is less than the allowable ratio of 0.100 [46, 47].

Pairwise comparisons of sub environmental criteria: As shown in Fig. 13, the sub environmental criterion that has the highest importance among the others is "Applicable environmental rules and regulations" at $42.8 \%$, accompanied by "Environmental impact" at $24.1 \%$, followed by $13.0 \%$ for waste management", $11.2 \%$ for "Intensity of energy exploitation in the production process", and $9.0 \%$ for "Intensity of utilization of available natural resources". The stability ratio for the comparison is 0.060 less than the allowable ratio of $0.100[46,47]$.

Pairwise comparisons of subsocial criteria: As shown in Fig. 14, the subsocial criterion that has the highest importance among the others is "Improving the employment situation" at $59.4 \%$, followed by "The distribution of incomes is equal" at $24.9 \%$, and finally $15.7 \%$ for "Improved quality of life and wellbeing". The stability ratio for the comparison is 0.050 , which is less than the allowable ratio of $0.100[46,47]$.

Table 7 summarizes the earlier figures, illustrating the weights of criteria, local subcriteria, and global subcriteria of the AHP model.

\section{Total Weight of Alternatives}

Table 7 lists the results of pairwise comparisons of the total weights of alternatives using Expert Choice. In the first column is the SD's criteria. Column 2 provides the weight of the criteria. Column 3 names the code for subcriteria. Columns 4 to 33 provide the priority of the construction industry categories as calculated by Expert Choice.

The table shows that the most important activity is building construction. The industry attains a preference of $13.9 \%$. The industry's addition to the domestic economy and ability to generate job opportunities for various disciplines and at diverse levels might explain this. According to data of the General Authority for Statistics in Saudi Arabia, the buildings sector accommodates 1,147,194 jobs and ranks third after trade/accommodations/food and industrial activity [9]. The water and sanitation works industries ranks second at $11.2 \%$, which shows the importance of this industry to the other remaining industries since this is considered the main request of other industries. The electrical activity industry represented $10.8 \%$, which is close to the weight of the water and sanitation works industry. In fourth place in the ranking is the road construction industry at $8.6 \%$; the researcher attributed the leading rank of this activity to the civic development witnessed in the Kingdom.

Mechanical works, electronic works, and landscaping are ranked fifth, sixth and seventh with weights of $6.5 \%$, $6.2 \%$, and $4.8 \%$, respectively, and are considered to form important industries that enhance the availability of job opportunities for a large number of workers. The dams industry is ranked eighth with a weight of $3.3 \%$, while city cleaning and waste disposal and communication technology industries ranked ninth and tenth with a priority $3.1 \%$. The maintenance building industry is ranked 11th with a weight of $2.8 \%$. The catering for medical centers industry is ranked twelfth with a weight of $2.5 \%$, while maintenance roads and landscaping industries are ranked $13^{\text {th }}$ and $14^{\text {th }}$, respectively, with a weight of $2.1 \%$. The findings from this research are consistent to some extend with the work done in Saudi Arabia and globally by [54-56].

The remaining industries achieve weights between $0.07 \%$ and $1.9 \%$. It is worth noting that the building, water and sanitations works, mechanical works, roads, and electronic works construction industry categories achieve the first rank in general due to the nature of these industries, providing a large number of employment opportunities, which also benefits social stability and influences the daily social activities of Saudi people's lives. The various maintenance activities were ranked in the lowest positions from the perspective of the experts involved in the research.

\section{Conclusions and Future Work}

This research investigates the criteria and indicators of the construction industry sector in Saudi Arabia in order to evaluate sustainability development. The major result is the evaluation of the priority value of the EES criteria for appraising the SD of KSA and the preference rank of investment alternatives in the economic activities of the construction business, which consists of 29 industrial activities. The level of importance for the 13 subcriteria is based on the pairwise comparisons conducted by professionals practicing in the construction sector. While scientists focused on sustainability of the environment, green and transport technology, urban land use, energy planning, and modeling, they did not concentrate on investigating the SD of different industrial tasks or measuring the relative importance of their EES criteria.

Most of the work done addressing sustainabilityrelated judgment-making focused on the issue as a multicriteria decision-making problem using AHP and fuzzy AHP. This research is applying an integrated approach combining SEM and AHP; it applies the SEM to define the affecting factors in the decision-making 
process. This investigation uses SmartPLS and Expert Choice software to design and analyze the collected data from Saudi experts working in construction industry categories. The results of SEM analysis were applied in the AHP model. Expert Choice designed the AHP model, which calculates the consistency ratio for judgments and values of criteria and subcriteria total weights of alternatives.

SmartPLS defines and analyzes the measurement and structural equation models based on 3 main criteria and 8 economic subcriteria, 8 environmental subcriteria, and 5 social subcriteria that are defined by experts working in the Saudi construction industry. Based on the analysis of the measurement model, a reliable structural model was designed to include 5 economic subcriteria, 5 environmental subcriteria, and 3 social subcriteria. Expert Choice formulates the AHP model to define the weights of the criteria, subcriteria, and preference percentage for alternatives. The results indicated that building projects ranked first at 13.9\%, followed by water and sanitation activities at $11.2 \%$, and then electrical works business at $10.8 \%$. Road work ranked fourth at $8.6 \%$, followed by mechanical activities at $6.4 \%$. The electronic works category ranked sixth at $6.2 \%$, and then landscaping works at $4.8 \%$. The dams category ranked eighth at $3.3 \%$ percent; city cleaning and waste disposal achieved $3.1 \%$, and the remaining categories achieved between $0.07 \%$ and $1.9 \%$.

SEM and AHP techniques offer the most suitable sustainability criteria and subcriteria ranking procedure, which fills the gap of defining the AHP model based on affecting factors. In the case of sustainability development, the existing literature neglects the sustainability model definition in both theory and practice and does not provide a method to help decisionmakers understand the relative importance of subfactors to the main criteria. The results obtained by this research work coincide with the work done by these referenced authors as in Saudi Arabia and globally [54-56].

The natural expansion of this research is to determine the correlations between the main and subcriteria based on the SEM technique. The work of sustainability model development for KSA is an open research area. Further investigation may focus on integrating the uncertainty of criteria weights into an MCDM application. In addition, it is important to note that the combination of different dimensions of sustainability performance remain questionable in terms of their compensability. The assignment of criteria weights, which represent their intensity of preference or importance, implies compensatory measures and trade-off among criteria, while this might be unacceptable for certain cases of SD.

\section{Conflict of Interest}

The authors declare no conflict of interest.

\section{References}

1. PATHAK P., SRIVASTAVA R.R., OJASVI Assessment of legislation and practices for the sustainable management of waste electrical and electronic equipment in India. Renewable and Sustainable Energy Reviews, 78, 220, 2017.

2. CHIEN BONG C.P., HO W.S., HASHIM H., LIM J.S., HO C.S., PENG TAN W.S., LEE C.T. Review on the renewable energy and solid waste management policies towards biogas development in Malaysia. Renewable and Sustainable Energy Reviews, 70, 988, 2017.

3. JABBOUR A.B.L DE S., JABBOUR C.J.C., LATAN H., TEIXEIRA A.A., DE OLIVEIRA J.H.C. Reprint of "Quality management, environmental management maturity, green supply chain practices and green performance of Brazilian companies with ISO 14001 certification: Direct and indirect effects." Transportation Research Part E: Logistics and Transportation Review, 74, 139, 2015.

4. GUALANDRIS J., KALCHSCHMIDT M. Developing environmental and social performance: The role of suppliers sustainability and buyer-supplier trust. International Journal of Production Research, 54 (8), 2470 , 2016.

5. YU W., CHAVEZ R., FENG M., WIENGARTEN F. Integrated green supply chain management and operational performance. Supply Chain Management, 19 (5/6), 683, 2014.

6. DE GIOVANNI P., ESPOSITO VINZI V. The benefits of a monitoring strategy for firms subject to the Emissions Trading System. Transportation Research Part D: Transport and Environment, 33, 220, 2014.

7. YUSOF N., ZAINUL ABIDIN N., ZAILANI S.H.M., GOVINDAN K., IRANMANESH M. Linking the environmental practice of construction firms and the environmental behaviour of practitioners in construction projects. Journal of Cleaner Production, 121, 64, 2016.

8. KSA. Ministry of Commerce and Investment. Media Center: Open Data, https://mci.gov.sa/en/MediaCenter/ open-data/Pages/default.aspx. 2018.

9. GaStat. General Authority for Statistics. General Authority for Statistics. Retrieved February 1, 2019, from https://www.stats.gov.sa/en 2018.

10. IKEDIASHI D.I., OGUNLANA S.O., ALOTAIBI A., A, Analysis of Project Failure Factors for Infrastructure Projects in Saudi Arabia: Approach, Journal of Construction in Developing Countries, Journal of Construction in Developing Countries 19, 2014.

11. MCCULLOUGH, D Saudi Arabia's green decree brings hopes of sustainability. The Guardian. Retrieved from http://www.theguardian.com/sustainable-business/saudiarabia-green-construction-oil-sustainability-environment 2014.

12. KSA. Contractor Classification Agency. Ministry of Municipal and Rural Affairs,Number of Contarctors Classsified by Field,. Retrieved February 1, 2019, from https://www.momra.gov.sa/ 2018.

13. DAVY A.J., WILLIS A.W. (1922?2006). Journal of Ecology, 94 (6), 1049, 2006.

14. RINGLE C.M., DA SILVA D., BIDO D.D.S. Structural Equation Modeling with the Smartpls. Revista Brasileira de Marketing, 13 (02), 56, 2014.

15. GARSON G.D. Software Review: Expert Choice Professional: Decision Support Software. Social Science Computer Review, 15 (2), 221, 1997. 
16. Central Bureau of Statistics. Statistical Yearbook of the. Retrieved from https://www.stats.gov.sa/en 2009.

17. UGWU O.O., HAUPT T.C. Key performance indicators and assessment methods for infrastructure sustainability-a South African construction industry perspective. Building and Environment, 42 (2), 665, 2007.

18. YATSALO B., GRITSYUK S., SULLIVAN T., TRUMP B., LINKOV I. Multi-criteria risk management with the use of DecernsMCDA: methods and case studies. Environment Systems and Decisions 36, 2016.

19. ALOTAIBI N., SUTRISNA M., CHONG H.-Y. Managing Critical Factors Causing Delays in Public Construction Projects in Kingdom of Saudi Arabia. Proceedings of the $2015\left(6^{\text {th }}\right)$ International Conference on Engineering, Project, and Production Management. Association of Engineering, Project, and Production Management. 2018.

20. HADDAD L.V.A.N. Building Sustainability Assessment throughout Multicriteria Decision Making. Journal of Construction Engineering, 2013, 9. Retrieved from http:// dx.doi.org/10.1155/2013/578671, 2013.

21. HUANG I.B., KEISLER J., LINKOV I. Multi-criteria decision analysis in environmental sciences: ten years of applications and trends. The Science of the total environment, 409 (19), 3578, 2011.

22. OLIVEIRA M.D., MATALOTO I., KANAVOS P. Multicriteria decision analysis for health technology assessment: addressing methodological challenges to improve the state of the art. The European Journal of Health Economics. 2019.

23. ANTUCHEVIČIENE J., ZAVADSKAS E.K., ZAKAREVIČIUS A. Multiple criteria construction management decisions considering relations between criteria. Ukio Technologinis ir Ekonominis Vystymas, 16 (1), 109, 2010.

24. DARJI V.P., RAO R.V. Intelligent Multi Criteria Decision Making Methods for Material Selection in Sugar Industry. Procedia Materials Science, 5, 2585, 2014.

25. ZAVADSKAS E.K., TURSKIS Z. A new additive ratio assessment (ARAS) method in multicriteria decisionmaking. Ukio Technologinis ir Ekonominis Vystymas, 16 (2), 159, 2010.

26. CUADRADO J., ZUBIZARRETA M., ROJÍ E., GARCÍA H., LARRAURI M. Sustainability-Related Decision Making in Industrial Buildings: An AHP Analysis. Mathematical Problems in Engineering, 2015, 1, 2015.

27. HASHEMKHANI ZOLFANI S., POURHOSSEIN M., YAZDANI M., ZAVADSKAS E.K. Evaluating construction projects of hotels based on environmental sustainability with MCDM framework. Alexandria Engineering Journal, 57 (1), 357, 2018.

28. HOSSAINI N., REZA B., AKHTAR S., SADIQ R., HEWAGE K. AHP based life cycle sustainability assessment (LCSA) framework: a case study of six storey wood frame and concrete frame buildings in Vancouver. Journal of Environmental Planning and Management, 58 (7), 1217, 2015.

29. SIERRA L.A., YEPES V., PELLICER E. A review of multi-criteria assessment of the social sustainability of infrastructures. Journal of Cleaner Production, 187, 496, 2018.

30. KAMARUZZAMAN S.N., LOU E.C.W., WONG P.F., WOOD R., CHE-ANI A.I. Developing weighting system for refurbishment building assessment scheme in Malaysia through analytic hierarchy process (AHP) approach. Energy Policy, 112, 280, 2018.
31. HASHEMINASAB H., GHOLIPOUR Y., KHARRAZI M., STREIMIKIENE D. Life cycle approach in sustainability assessment for petroleum refinery projects with fuzzy-AHP. Energy and Environment, 29 (7), 1208, 2018.

32. MEDINECKIENE M., ZAVADSKAS E.K., BJÖRK F., TURSKIS Z. Multi-criteria decision-making system for sustainable building assessment/certification. Archives of Civil and Mechanical Engineering, 15 (1), 11, 2015.

33. SALVADO M.F., AZEVEDO S.G., MATIAS J.C.O., FERREIRA L.M. Proposal of a sustainability index for the automotive industry. Sustainability (Switzerland), 7 (2), 2113, 2015.

34. KIM M.S., LEE E.B., JUNG I.H., ALLEMAN D. Risk assessment and mitigation model for overseas steel-plant project investment with analytic hierarchy process-fuzzy inference system. Sustainability (Switzerland), 10 (12), 4780, 2018

35. ALYAMI S.H., REZGUI Y., KWAN A. The development of sustainable assessment method for Saudi Arabia built environment: weighting system. Sustainability Science, $\mathbf{1 0}$ (1), 167, 2015.

36. JATO-ESPINO D., CASTILLO-LOPEZ E., RODRIGUEZHERNANDEZ J., CANTERAS-JORDANA J.C. A review of application of multi-criteria decision making methods in construction. Automation in Construction, 45, 151, 2014.

37. CUADRADO J., ZUBIZARRETA M., ROJI E., LARRAURI M., ALVAREZ I. Sustainability assessment methodology for industrial buildings: three case studies. Civil Engineering and Environmental Systems, 33 (2), 106, 2016.

38. HSUEH S.-L., YAN M.-R A Multimethodology Contractor Assessment Model for Facilitating Green Innovation: The View of Energy and Environmental Protection. The Scientific World Journal, 2013, 1, 2013.

39. JOHNSON C.S. Principles of Sustainable Development edited by F. Douglas Muschett. Delray Beach, FL: St. Lucie Press, 1997.176 pp., with index, U.S. \$49.95 (hardcover). (ISBN 1574440799. The Journal of Environment \& Development, 6 (4), 465, 2007.

40. ALI F., RASOOLIMANESH S.M. An assessment of the use of partial least squares structural equation modeling (PLS-SEM ) in hospitality research International Journal of Contemporary Hospitality Management Article information: Journal of the Academy of Marketing Science 409, 2018.

41. HWANG H., TAKANE Y. Generalized structured component analysis: A component-based approach to structural equation modeling. Generalized Structured Component Analysis: A Component-Based Approach to Structural Equation Modeling. Chapman and Hall/CRC. 2014.

42. LATAN H. Partial Least Squares Structural Equation Modeling. International Series in Operations Research \& Management Science. Springer International Publishing. 2018.

43. TAKANE Y., HWANG H. Regularized Multiple Correspondence Analysis. In Multiple Correspondence Analysis and Related Methods (pp. 259-279). Chapman and Hall/\{CRC $\} .2010$.

44. KETCHEN D.J. A Primer on Partial Least Squares Structural Equation Modeling. Long Range Planning. Springer International Publishing. 2013.

45. GEFEN RIGDON, STRAUB. Editor's Comments: An Update and Extension to SEM Guidelines for 
Administrative and Social Science Research. MIS Quarterly, 35 (2), iii, 2011.

46. SAATY T.L., VARGAS L.G. Models, Methods, Concepts \&amp; Applications of the Analytic Hierarchy Process. International Series in Operations Research \& Management Science. Springer US. 2001.

47. SAATY T.L. The analytic hierarchy and analytic network processes for the measurement of intangible criteria and for decision-making. International Series in Operations Research and Management Science. Springer New York. 2016.

48. KSA. Saudi Industrial Development Fund. Media Center: Open Data. Retrieved from http://www.sidf.gov.sa/en/ MediaCenter/OpenData/Pages/default.aspx 2018.

49. LONGARAY A.A., ENSSLIN L. Use of Multi-Criteria Decision Aid to Evaluate the Performance of Trade Marketing Activities of a Brazilian Industry. Management and Organizational Studies, 2 (2), 2015.

50. KAINULAINEN T., LESKINEN P., KORHONEN P., HAARA A., HUJALA T. A statistical approach to assessing interval scale preferences in discrete choice problems. Journal of the Operational Research Society, $\mathbf{6 0}$ (2), 252, 2009
51. NITZL C. Management accounting and partial least squares-structural equation modelling (PLS-SEM): Some illustrative examples. International Series in Operations Research and Management Science. Springer International Publishing. 2018.

52. GEFEN D., STRAUB D., BOUDREAU M.-C. Structural Equation Modeling and Regression: Guidelines for Research Practice. Communications of the Association for Information Systems, 4, 2018.

53. BAGOZZI R.P. Evaluating Structural Equation Models with Unobservable Variables and Measurement Error: A Comment. Journal of Marketing Research, 18 (3), 375, 2006.

54. ADEBAYO BELLO I., BIN ISMAIL M.N. Solid Waste Management in Africa: A Review. International Journal of Waste Resources, 6 (2), 13, 2016.

55. OUDA O.K.M., CEKIRGE H.M. Roadmap for Development of Waste-to Energy Facility in Saudi Arabia. American Journal of Environmental Engineering, 3 (6), 267, 2013.

56. ANAND A., KHAN R.A., WANI M.F. Development of a sustainability risk assessment index of a mechanical system at conceptual design stage. Journal of Cleaner Production, 139, 258, 2016. 